\title{
Rebel Group Protection Rackets: Simulating the Effects of Economic Support on Civil War Violence
}

\author{
Frances Duffy, Kamil C. Klosek, Luis G. Nardin (D, and Gerd Wagner
}

\begin{abstract}
Rebel groups engage in a series of economic transactions with their local populations during a civil war. These interactions resemble those of a protection racket, in which aspiring governing groups extort the local economic actors to fund their fighting activities and control the territory. Seeking security in this unstable political environment, these economic actors may decide to flee or to pay the rebels in order to ensure their own protection, impacting the outcomes of the civil war. We present a simulation model (executable at https://gnardin.github.io/RebelGroups) that attempts to capture the decision-making and behavior of the involved actors during protection racket interactions as well as the cooperation and competition between rebel groups to control territory. Our model reveals insights about the mechanisms that are helpful for understanding violence outcomes in civil wars, and the conditions that may lead rebel groups to prevail. Analysis of various scenarios demonstrates the impact that different security factors play on civil war dynamics. Using Somalia as a case study, we also assess the importance of the rebel groups' economic bases of support in a real-world setting.
\end{abstract}

Keywords Enterprise - Rebel group - Protection racket - Somalia - Civil war · Agent-based model · Simulation

Frances Duffy and Kamil C. Klosek contributed equally to this chapter.

\section{F. S. Duffy}

University of North Carolina at Chapel Hill, Chapel Hill, NC, USA

e-mail: frncs@live.unc.edu

K. C. Klosek

Charles University, Prague, Czech Republic

e-mail: kamil.klosek@fsv.cuni.cz

L. G. Nardin $(\bowtie) \cdot$ G. Wagner

Brandenburg University of Technology, Cottbus, Germany

e-mail: nardin@b-tu.de; wagnerg@b-tu.de

E. Deutschmann et al. (eds.), Computational Conflict Research,

Computational Social Sciences, https://doi.org/10.1007/978-3-030-29333-8_11 


\section{Introduction}

How do rebel groups control territory and engage with the local economy during civil war? Charles Tilly's seminal War and State Making as Organized Crime (Tilly, 1985) posits that the process of waging war and providing governance resembles that of a protection racket, in which aspiring governing groups extort local populations to gain power, and civilians or businesses pay to ensure their own protection. We present an agent-based simulation model that attempts to capture the decisionmaking and behavior of the actors involved: rebel groups and enterprises. The model is available online at https://gnardin.github.io/RebelGroups as a web-based simulation and can be run in any modern web browser.

The use of agent-based modeling in civil war research is not a new endeavor. The groundwork is laid by Epstein (2002), who analyzes the conditions under which individuals may mobilize and protest. He examines factors such as the legitimacy of a political system, risk-aversion of potential protesters, police strength, and geographic reach. Several researchers have since expanded upon Epstein's work by focusing on greed and grievances in rebellious movements (Goh et al., 2006), crime (Fonoberova et al., 2018), and network effects caused by the spread of media (Lemos et al., 2016). Our model also builds upon earlier research by focusing on civil war dynamics that could emerge after the initial rebellion. It focuses on the relationships between economic and security factors as determinants of interrebel warfare by treating collective rebel groups as well as business enterprises as individual agents.

Conceptually, the opportunity for rebel groups to engage in extortion of local populations most often arises either in a condition of relative anarchy or when the incumbent government is too weak to protect local enterprises itself (Fjelde and Nilsson, 2012). Some scholars theorize that a security dilemma influences actors to support or form rebel groups for protection in order to balance against threats of violence and competition from one another (Posen, 1993). While this theory may capture some of the motivation for enterprises to seek security, it does not explain how this process takes place and why rebel groups, who may face varying degrees of security threats to their own interests, would be motivated to take and hold territory while controlling local populations.

Several scholars address the question of when rebel groups choose to develop a relationship with civilians and when they choose to attack or loot them instead. Weinstein (2006) argues that the presence of outside support and lootable resources increases the likelihood that rebel groups will fail to seek a cooperative relationship with civilian populations under their control, because they can expand economically without extorting local businesses. By contrast, rebel groups that fight on behalf of ideological goals may be more likely to seek the cooperation of local communities, relying on them for provision or extortion of resources and providing protection or other benefits in order to maintain this relationship (Weinstein, 2006). Further, relatively weak rebel groups with rising battlefield costs, which are not strong enough to engage in extortion activities, may also loot civilians rather than engage in 
a process of periodic extraction from the local population (Wood, 2014). As losses increase, rebels are more likely to desert the rebel group, die in heavy losses, or be expelled as the group can no longer afford to compensate them (Weinstein, 2005).

Therefore, the economic conditions in a conflict territory, as well as the funding characteristics of a rebel group, influence the extortion of local enterprises. These extortion activities have consequences for the behavior of rebel groups in conflict. When two different rebel groups contest territory or seek the extortion of enterprises under the control of another group, we can expect fighting between the rebels (Fjelde and Nilsson, 2012). The groups may seek greater economic gains, continued dominance over an area of territory, or simply to protect and defend the local populations that they themselves extort. These incentives may motivate competition and battles between groups, which depend on the available resources and capabilities. Thus, the extortion racket they develop permits a continued process of expansion aiming at hegemony and protection of the territory.

Those who support a rebel group and benefit from its protection may provide information or intelligence on the group's rivals, or even be recruited to join its ranks which further increases the group's fighting capacity (Barter, 2012; Kalyvas, 2006). Apart from providing temporary jobs as fighters, local populations can also economically benefit depending on the status quo ante. For instance, Leeson (2007) and Powell et al. (2008) find that the statelessness conditions of Somalia between 1991 and 2005 were more favorable for local business actors than the previous predatory regime of Siad Barre. This holds mainly in economic sectors that are less dependent on government authority but suffer due to corruption and forced seizures of assets. Alternatively, if rebel groups are unable to provide protection following extortion or they themselves engage in violent attacks and looting, business actors may choose to support a rival group or even to flee. Whether due to direct attacks or inter-rebel group fighting, an increase in the severity of violence motivates business actors to flee for safety (Barter, 2012; Steele, 2009).

Ultimately, a stable point may be reached at which rebel groups gain enough territory and sufficient trust from the local population to establish themselves as a legitimate governing institution. This shift may come with local adjudication responsibilities and public goods provision. Having established an ad hoc local governing institution, the system transitions away from the competitive security environment and the system is no longer in anarchy. At this point, one group achieves hegemony over all competitors. A stalemate may also be reached if two or more rebel groups balance against each other's power, with neither group gaining the capability to seek the extortion of its opponent's population (Walt, 1985; Waltz, 1979).

As civil war research continues to probe the political mechanisms that fuel local disputes and the origination of violence (e.g., Østby (2008); Cunningham (2013); Cederman and Vogt (2017); Walter (2017)), our agent-based simulation model explores the economic relationships of rebel groups with their local populations. The model captures the extortion of local enterprises by rebel groups, their decisions to 
expand their controlling territory, as well as the decisions of enterprises whether to report extortion or to flee. We use the model to perform security-related experiments using a theoretical system of three warring rebel groups, examining their impacts on the economy and the importance of their economic bases of support for their sustainability during a civil war. This analysis provides insights for understanding the causes and byproducts of rebel competition in present-day conflicts, such as the case of Somalia. We therefore also apply the model to historical scenarios experienced over the evolution of Somalia's civil war and derive some initial implications from our findings.

\section{Theoretical Underpinnings}

Intrastate armed conflicts or civil wars require rebel groups to raise revenue and gather resources in order to mobilize and to sustain the offensive and defensive potential necessary for long-term survival. Internally, a rebel group also needs to establish a structured organization to sustain group cohesion until the armed conflict ceases. Both mobilization and structuring incur distinguishable costs on rebel actors (Wennmann, 2009). According to Olson (1993), those rebel groups that are able to monopolize violence in a confined territory and establish themselves as the predominant local institutional structure are able to extract a permanent revenue stream through local taxation. This provides groups with crucial advantages as compared to "roving" actors who survive on incidental and temporary extraction gains.

We assume the interactions of rebel groups in an anarchic environment. No superior actor can alleviate information asymmetries or commitment problems. In their pursuit of survival, rebel groups rely on their own capacities and are unrestricted in their choice of actions. This assumption is prevalent in the study of International Relations, in which states are the highest order actors. It is also popular in civil war studies, in particular in literature on bargaining failures (Spaniel and Bills, 2016; Nygård and Weintraub, 2014) and discussions of the ethnic security dilemma (Roe, 1999; Johnson, 2015). Similarly, Olson (1993) uses the assumption of anarchy as a backdrop of inter-group competition development.

Academic research has also examined different types of rebel revenue streams. Armed actors during the Cold War were primarily financed by external patrons such as the USA, the Soviet Union, Cuba, China, France, and other countries posturing on the world stage (Schmidt, 2013). In the 1990s, in the wake of the fall of the Soviet Union and the ideological contention that accompanied it, the world established new norms of non-intervention, and sub-national armed actors needed to find replacements for their former patrons. Natural resource extraction featured most prominently (Lujala, 2008; Lujala et al., 2005; Collier et al., 2008), in addition to migrant and diaspora remittances (Regan and Frank, 2014; Escribà-Folch et al., 2018) and looting (Wennmann, 2011). 
However, rebel groups may still rely on local extraction of funds and supplies. In order to achieve an enduring and consistent revenue stream, rebel groups create protection rackets against business actors operating within the area in which the armed conflict takes place. For example, in the Niger Delta region of Nigeria, local rebel groups kidnap corporate employees and release them in exchange for ransom (Ikelegbe, 2006). Revenues obtained through piracy also often end up in rebel pockets (Daxecker and Prins, 2017). Business elites in Somalia are required by local warlords to pay road taxes in addition to periodical payments in exchange for security (Ahmad, 2015). During civil wars in Sierra Leone and Liberia, rebel leaders instructed foot soldiers to forcibly extract revenues from local civilians, which they did through the manning of crucial local and cross-border trade checkpoints (Reno, 1999). All actions occurred in rebel-held territory and allowed rebel groups to pay for food, arms, and shelter to their members.

\subsection{Rebel Group Extortion and Looting}

Rebel groups have two potential options for obtaining revenue from local enterprises (Shearer, 2000). First, they may extort enterprises by periodically extracting a proportion of their revenue, which incrementally increases their wealth. The rebel group must take care that the extracted amount does not endanger the sustainability of the enterprise; otherwise, it will be left without a continuous revenue stream in the future. The alternative approach is looting, in which the rebel group seizes all of the wealth of an enterprise. This occurs primarily under three conditions. First, the rebel group behaves like a "roving bandit" and simply pillages the enterprise without any desire to control the territory where it is located (in the model, "territory" is meant not as a specific geographic location but in a metaphoric sense). Second, the rebel group punishes and loots enterprises that pay extortion money to an adversary rebel group. Third, a weak rebel group may find itself in fierce competition with a much stronger rebel group. In order to compensate for the strength of its opponent, it may attempt to collect more wealth over a short period of time through repeated looting.

\subsection{Enterprise Fleeing}

Enterprises have the inherent desire to create wealth and generate income, even under conditions of civil war. However, assuming no military or defensive capabilities of their own, and assuming no official government protection, they rely on protection provided by armed rebel groups. Cooperation with a group may be beneficial. If a rebel group limits its extortion amount to allow continued revenue earnings and growth, an enterprise can sustain itself and even overcome its 
competitors who incur losses due to insecurity. However, if an enterprise is depleted of its wealth due to looting, it may decide to flee from the armed conflict rather than attempting to rebuild its business, since it might risk further unwanted extraction or threats to physical safety. For instance, Collier and Duponchel (2013) show that during 10 years of civil war in Sierra Leone from 1992 to 2001, businesses shrunk in size.

\subsection{Enterprise Reporting}

Enterprises may favor one particular rebel group as determined by the fraction of their extorted revenue. A favored group extracts the least amount of money as compared to its rivals. Assuming a purely economic system, we do not consider shared ethnic identity or other aspects of the group's reputation as influential towards an enterprise's preference. Reporting occurs when enterprises within the territory of one rebel group are extorted by a competing group. We base this logic on the experiences of enterprises who are extorted by mafia groups (see Nardin et al., 2016). An Enterprise may choose to report the extortion attempt to its preferred (main) rebel group based on the amount extracted.

\subsection{Rebel Group Fighting and Expansion}

Fighting is the attempt of rebel groups to achieve hegemony during a civil war and to eliminate competing groups. We summarize the conditions for rebel fighting under three broad assumptions. First, two groups fight due to a competitive desire for power and expansion. Each group has an inherent wish to expand, and the more powerful a group, the more likely that it initiates fighting in order to conquer other groups. Fjelde and Nilsson (2012) have examined the proclivity of rebel groups engaged in armed conflict with one another, showing that larger capability discrepancies result in an increased probability of fighting. Second, rebel groups may wish to extort funds and resources from enterprises already controlled by a rival group. This broadens the economic base of a rebel group and allows it to recruit more soldiers, which in turn renders the group more competitive. The third influencing condition is enterprise reporting. Once extorted, an enterprise may choose to report to its main rebel group, increasing the probability of fighting by revealing strategic information about the group's whereabouts. A group successfully expands when enterprises are reallocated from the losing to the winning rebel group. 


\subsection{Rebel Group Cooperation}

Under conditions of anarchy, rebel groups may counterbalance against one another in order to achieve power parity, seeking to prevent the achievement of hegemony by any one group. Therefore, two weaker rebel groups may combine forces and cooperate against a stronger group. This closely resembles the logic of balance-ofpower in International Relations theory (Walt, 1985; Waltz, 1979). We apply this concept to sub-national actors in a civil war. Cooperation between relatively weak groups becomes more likely the higher the power disparity between an attacking rebel group and its targets. We assume only defensive cooperative behavior; groups only join forces in order to defend against attacks from a stronger group, rather than offensive in which multiple groups combine forces in attacking a larger group. We also assume that the costs of fighting incurred by an attacker are dependent on the combined strength of the cooperating target rebel groups, who may be relatively easy or relatively difficult to defeat. The costs inflicted by the attacker are distributed among the cooperating target groups inversely proportional to their strength.

\subsection{Rebel Group Recruitment}

Over time, a rebel group hires or "recruits" new rebels to increase its size and maintain its fighting capabilities. The exact number of rebel recruits is determined by the following conditions. First, the cost of hiring and retaining recruits must be deducted from the group's overall wealth. Therefore, the amount of wealth determines how many rebels can be hired in the future. Second, rebels are constrained by recruit availability when seeking new hires. We assume a constraint that limits groups from recruiting new members who number more than a certain percentage of their current size. Rebel groups are unlikely to double or triple in size during the relatively short time periods of intermittent recruitment decisions, although they may substantially grow over the longer term. Third, the power disparity between rebel groups determines the rate of recruitment. The larger the power disparity, the slower the larger rebel group grows. Since an increase in group size increases the probability of winning a fight, the severity of damage to the opponent, and the costs of financing, growth experiences a decreasing marginal return. We assume that once a global power ratio of $4: 1$ is reached (this means that the largest rebel group has four times more rebels compared to the number in opposition), the hegemonic rebel group pauses recruitment. This choice underlines the marginal benefits a rebel group enjoys by growing in size. Reaching a power preponderance of this scale makes any increase in size minuscule as it becomes highly improbable that the remaining rebel groups will overpower the hegemon. Since the civil war is permanent in this model, the hegemon still attempts to expand and will eventually crowd out the remaining rebel groups. 


\section{Rebel Group Protection Rackets Model}

In this section, we describe in detail the Rebel Group Protection Rackets model (Sect.3.1), introduce the model variables that define a scenario (Sect.3.2), and briefly describe implementation details of the model (Sect. 3.3).

\subsection{Model Description}

Based on the assumptions presented above, we conceptualize an agent-based model of protection rackets in a civil war conflict zone inside a weak or failed state. ${ }^{1}$

Here we adopt the Object Event Modeling and Simulation paradigm, which uses the concepts of object types, event types, and event rules for modeling discrete dynamic systems (Wagner, 2018). The objects of the system being modeled may be passive entities or active entities ("agents"), while the events that happen in this system may represent environment events or actions of an agent. Objects and events are classified by object types and event types, which may define type-specific properties (and operations). Event rules represent causal regularities leading to changes in the states of affected objects and to follow-up events.

Figure 1 shows the information design model for the Rebel Group Protection Rackets model, which is composed of two object types, RebelGroup and Enterprise,

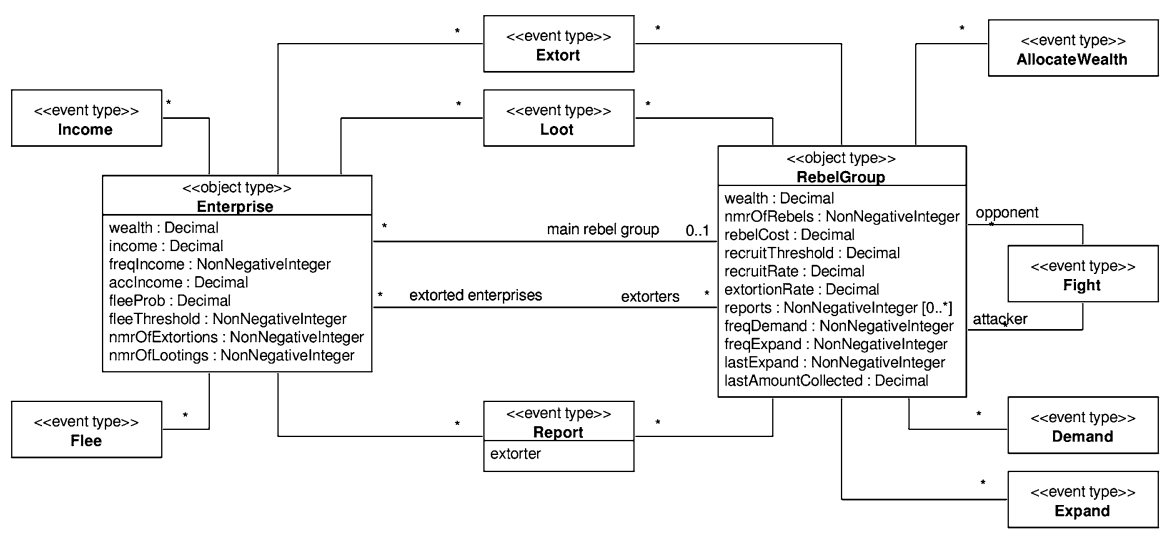

Fig. 1 Information design model for the Rebel Group Protection Rackets model using unified modeling language (UML) class diagram. The * symbol represents association cardinality, e.g., in the main rebel group association, one RebelGroup can be the main rebel group of multiple enterprises, but one enterprise can have at most one main rebel group

\footnotetext{
${ }^{1}$ Notice that this is a stylized fact model; thus, we adopt several simplifications that nevertheless capture the main characteristics of the phenomenon of interest.
} 
and nine event types, AllocateWealth, Demand, Expand, Extort, Fight, Flee, Income, Loot, and Report.

Enterprises represent local businesspersons and liberal professionals who conduct business in a territory that may be under the control of a RebelGroup. Enterprises aim to make enough profit to support their household by avoiding, if possible, the payment of extortion money.

RebelGroups are armed groups that compete among themselves aiming to enlarge their territorial domain ${ }^{2}$ by increasing the number of Enterprises under their control. A RebelGroup may have multiple Enterprises under its control (extorted enterprises ${ }^{3}$ association) and an Enterprise can be under the control of at most one RebelGroup at any moment (main rebel group association).

A RebelGroup is composed of a number of rebels (nmrOfRebels) that define the size and strength of a RebelGroup. The strength of a RebelGroup can be evaluated in relation to all other RebelGroups (i.e., global strength) or in relation to an opponent RebelGroup (i.e., relative strength). The global strength is calculated as the RebelGroup's number of rebels divided by the total number of rebels of all RebelGroups. The relative strength is calculated as the RebelGroup's number of rebels divided by the sum of rebels of the RebelGroup and its opponent.

RebelGroups and Enterprises interact via a set of events that are generated exogenously (e.g., Demand, Expand, and Income events) or endogenously (e.g., AllocateWealth, Extort, Fight, Flee, Loot, and Report events). Exogenous events are recurrently generated based on some defined frequency. Endogenous events are caused by some other event. These types of events can be combined to define processes that are composed of an exogenous event acting as process initiator followed by a series of endogenous events. There are three processes in our model: Income Process, Demand Process, and Expand Process.

\subsubsection{Income Process}

The Income Process is composed of a single exogenous Income event. Each Enterprise is associated with an Income event, which causes the Enterprises to periodically (freqIncome) receive an income (income) corresponding with their business activities. The income received increases the Enterprise's wealth (wealth) and its accumulated income (accIncome). The accumulated income represents the revenue received by the Enterprise since the last time it was extorted or looted, and it is used for the calculation of the extortion amount requested by the RebelGroups.

\footnotetext{
${ }^{2}$ In the model, "territory" is abstract and it does not mean a specific geographic location.

${ }^{3}$ The Monospace font is used to indicate properties and associations presented in the information design model (Fig. 1).
} 


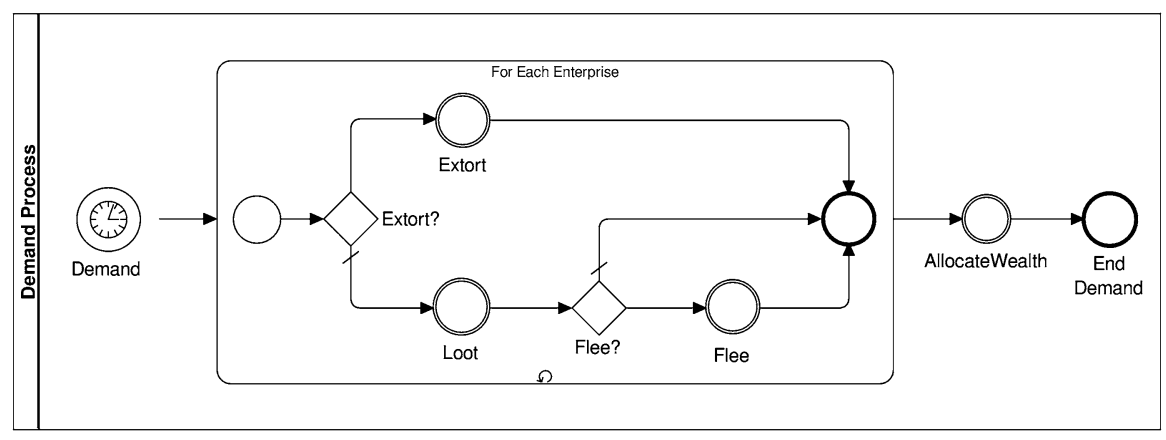

Fig. 2 Diagram illustrating the series of events and their interrelationships in the Demand Process

\subsubsection{Demand Process}

RebelGroups control portions of the territory and they periodically demand resources from the Enterprises under their control in order to support their fighting efforts.

Figure 2 illustrates the series of events composing the Demand Process that is periodically initiated by the Demand event.

There is one Demand event associated with each RebelGroup, which makes RebelGroups periodically ( $\mathrm{freqDemand}$ ) decide whether to extort (Extort event) or loot (Loot event) the Enterprises under their control. The decision whether to extort or loot is individually made by the RebelGroup for each Enterprise, but all Enterprises under the RebelGroup's control are extorted or looted at the same time. The individual decision whether to extort or loot is probabilistically based on the RebelGroup's global strength. Thus, weaker RebelGroups have a greater probability of looting the Enterprises under their control than stronger RebelGroups due to the greater pressure on the former to extract resources quickly to increase in size and become more competitive.

If deciding to extort (Extortion event), RebelGroups request a fraction (extortionRate) of the Enterprises' accumulated income (accIncome) as extortion payment. Enterprises pay the lesser between the demanded amount and their wealth. This amount is transferred from the Enterprise to the RebelGroup. Thus, RebelGroups increase their wealth (wealth) and the value of the last amount collected (lastAmountCollected) accordingly, and Enterprises decrease their wealth (wealth) by the amount of extortion money paid, reset their accumulated income (accIncome) to zero, and increase their number of extortions by one (nmrofExtortions).

When looting occurs (Loot event), Enterprises transfer their total amount of wealth to a RebelGroup. Thus, RebelGroups increase their wealth (wealth) and the value of the last amount collected (lastAmountCollected) accordingly, and Enterprises reset both their wealth (wealth) and accumulated 
income (accIncome) to zero, and increase by one their number of lootings (nmrOfLootings). Due to looting, however, an Enterprise may flee (i.e., leave the simulation) with a certain probability (fleeProb) or if the number of previous endured lootings is greater than a certain threshold (fleeThreshold). If an Enterprise decides to flee (Flee event), the Enterprise is removed from the list of extorted Enterprises and from the simulation.

After all demands are complete, RebelGroups reallocate their resources (AllocateWealth event). First, RebelGroups compensate their rebels, but if they do not have enough wealth to compensate all of them, they reduce their number of rebels by the difference between the wealth and the total compensation divided by the cost per rebel (rebel Cost).

Additionally, the RebelGroup may recruit or expel rebels if the amount collected since the last wealth allocation was less than the amount necessary to compensate the rebels. The number of rebels recruited (nmrRecruit) or expelled (nmrExpel) by a RebelGroup is defined by

$$
\text { delta }=\frac{\text { lastAmountCollected }-(\text { nmrOfRebels } \times \text { rebelCost })}{\text { rebelCost }},
$$

nmrRecruit $=\min ($ delta $\times(1-$ globalStrength $)$, nmrOfRebels $\times$ recruitRate $)$,

nmrExpel $=\min ($ nmrOfRebels, delta) .

\subsubsection{Expand Process}

RebelGroups intrinsically try expanding their territorial control over new Enterprises by fighting other RebelGroups or simply extracting resources from these Enterprises.

Figure 3 illustrates the series of events comprising the Expand Process that is periodically initiated by the Expand event.

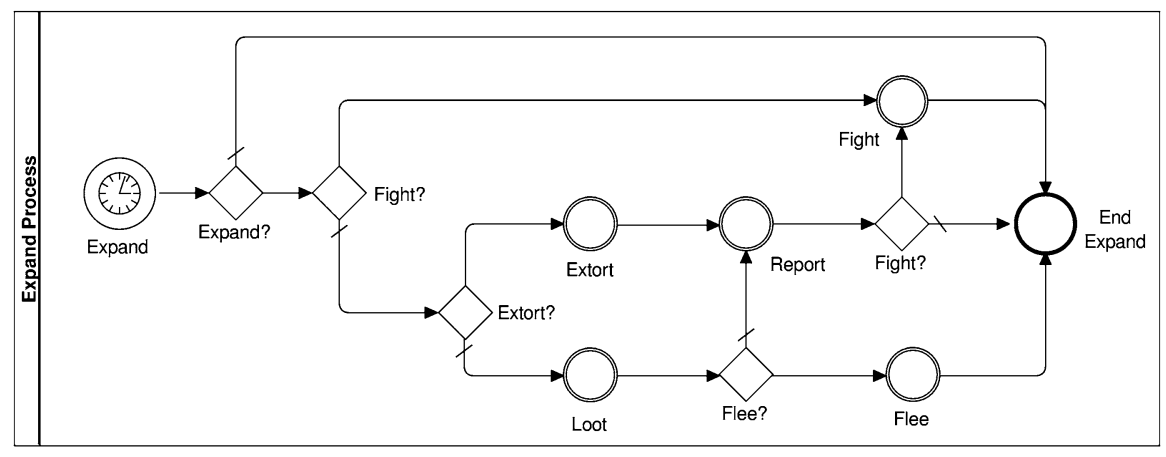

Fig. 3 Diagram illustrating the series of events and their interrelationships in the Expand Process 
There is one Expand event associated with each RebelGroup, which makes RebelGroups periodically (freqExpand) choose to expand territory if they have rebels and there are still Enterprises not under their control. The expansion decision also depends on a RebelGroup's global strength and the elapsed time since its last expansion. Stronger RebelGroups have greater opportunity to expand their domain, yet weak RebelGroups increase their chance of expanding as time elapses. Thus, the probability of a RebelGroup deciding to expand is defined by

$$
\operatorname{expandProb}\left(\alpha, t, t_{\text {last }}\right)=\frac{1}{1+e^{-\alpha\left(t-t_{\text {last }}\right)}},
$$

where $\alpha$ is the RebelGroup's global strength, $t$ is the current time, and $t_{\text {last }}$ is the last time the RebelGroup expanded (lastExpansion).

If the RebelGroup decides to expand, then it evaluates all Enterprises not under its control and chooses one Enterprise randomly with a probability inversely proportional to the Enterprise's wealth (i.e., poorer Enterprises are chosen with greater probability). If the chosen Enterprise is already under the control of another RebelGroup, the expanding RebelGroup decides whether to fight against the Enterprise's main RebelGroup or to simply extort or loot the Enterprise. The probability of a RebelGroup deciding to fight is defined by

$$
\text { fightExpandProb }(\beta)=\frac{1}{1+e^{-\beta}},
$$

where $\beta$ is the RebelGroup's relative strength with the main RebelGroup of the Enterprise adjusted to the scale $[-1,1]$ using the function $f(x)=2 x-1$.

The decision to fight is unilaterally made by the attacking RebelGroup (Fight event). However, if the opponent is weaker than the attacker, it may form an alliance with another RebelGroup with a probability equal to the difference between the attacker's global strength and its own. If the opponent decides to form an alliance, the alliance is formed with the first randomly chosen other RebelGroup that generates an alliance stronger (sum of both RebelGroups' global strength forming the alliance) than the attacker. If the constraint is not fulfilled with any other RebelGroup, no opposition alliance is formed.

The attacker and its opponent (a single RebelGroup or an alliance) are then categorized based on their global strength as the strong and the weak RebelGroups. The strong RebelGroup has a probability of winning the fight equal to the relative strength between itself and the weak RebelGroup. If the strong RebelGroup does not win the fight, the weak RebelGroup has a probability of winning the fight equal to the relative strength between itself and the strong RebelGroup.

The fight winner receives a specific number of Enterprises from the loser. These Enterprises are chosen randomly among the loser's list of extorted Enterprises. If the winner or loser is an alliance, then the distribution of Enterprises is determined using the inverse of the relative strengths between the allied RebelGroups.

In a fight, both the attacker and opponent (RebelGroup or formed alliance) suffer losses of rebel numbers. The loss is proportional to the relative strength of the 
opposing RebelGroup or alliance. The loss among RebelGroups forming an alliance is inversely proportional to their relative strength.

However, if the RebelGroup does not fight to expand, then the RebelGroup decides whether to extort or loot the chosen Enterprise with probability equal to its global strength.

Enterprises extorted by a different RebelGroup than their main RebelGroup always report the action of the former to the latter (Report event). Looted Enterprises, however, decide whether to report or flee.

If a RebelGroup is notified that another RebelGroup is extracting resources from Enterprises under its control, then it decides whether to fight the invader with a probability defined by

$$
\text { fightReportProb }(\beta, x)=\frac{1}{1+e^{-\beta x}},
$$

where $\beta$ is the RebelGroups' relative strength adjusted to the scale $[-1,1]$, and $x$ is the number of reports that the RebelGroup has already received about the invader (reports). In the case of a fight, the RebelGroups interact as previously described and the number of reports associated with the invader RebelGroup is reset to zero.

All RebelGroups' decisions to expand and fight are probabilistic and defined based on the sigmoid function of the form $f(x)=\frac{1}{1+e^{-x}}$, where $x$ combines multiple factors relevant to the decision being made. The choice for this function was motivated by (1) its boundedness to the range [0,1]; thus, the result can be directly applied to make a probabilistic decision, and (2) its S-shaped curve that grants a smooth decision transition between extremes, yet it has an initial lag period of slow growth and an end period of reduced growth-rate.

\subsection{Scenario and Initialization}

A simulation scenario, also simply called scenario, specifies the initial objects, the initial events, and the initial values of model variables briefly described in Table 1.

An experiment is defined on top of a simulation scenario by modifying one or more variable settings according to the definitions of the experiment's parameters. In the initialization of the simulation scenario, the specified number of RebelGroups and Enterprises are created and their properties are initialized using the corresponding model variables value defined in the scenario. Exceptions are those properties that (1) depend on calculations like the RebelGroup's wealth, which is set to the number of rebels multiplied by the cost per rebel (nmrOfRebels * RG Rebel Cost), and (2) depend on model variables defined as probability distributions like RebelGroup's freqDemand and freqExpand, and Enterprise's freqIncome and income, which are set with a number drawn from their respective model variable distribution settings. 
Table 1 Model variables defining a scenario

\begin{tabular}{|c|c|}
\hline Model variable & Description \\
\hline Simulation End Time & Length of the simulation run \\
\hline Random Seed & Random generator's seed \\
\hline Number Enterprises & Number of Enterprises \\
\hline Income $e^{\mathrm{b}}$ & Enterprise's income \\
\hline Income Frequency ${ }^{\mathrm{c}}$ & Frequency Enterprises receive income \\
\hline Flee Probability $^{\mathrm{c}}$ & Probability for looted Enterprises to flee \\
\hline Flee Threshold ${ }^{\mathrm{C}}$ & Number of loots Enterprises endure before fleeing \\
\hline Number Rebel Groups & Number of Rebel Groups \\
\hline$R G$ Size $e^{\mathrm{a}}$ & Initial number of rebels per Rebel Group \\
\hline RG Prop. Enterprises ${ }^{\mathrm{a}}$ & Proportion of the initial number of Enterprises per Rebel Group \\
\hline RG Extortion Rate R $^{\mathrm{a}}$ & Proportion of the Enterprise's accumulated income to extort \\
\hline RG Rebel Cost $t^{\mathrm{a}}$ & Cost per rebel \\
\hline RG Recruit Threshold ${ }^{\mathrm{a}}$ & Threshold of the Rebel Groups' strength to stop recruiting \\
\hline RG Recruit Rate ${ }^{\mathrm{a}}$ & Maximum size increase per wealth reallocation \\
\hline RG Demand Frequency ${ }^{\mathrm{a}, \mathrm{b}}$ & Frequency Rebel Groups decide racketeering Enterprises \\
\hline$R G$ Expand Frequency ${ }^{\mathrm{a}, \mathrm{b}}$ & Frequency Rebel Groups decide expanding \\
\hline Fight Expansion & Number of Enterprises transferred from loser to winner of fight \\
\hline
\end{tabular}

${ }^{a}$ List with the same number of elements as the Number Rebel Groups

${ }^{\mathrm{b}}$ Value is the mean and standard deviation defining a normal distribution

${ }^{\mathrm{c}}$ Value is the minimum and maximum values of a uniform distribution

\subsection{Implementation}

We implement our model using the JavaScript-based Object Event Simulation framework OESjs, ${ }^{4}$ which is an open-source web-based simulation platform that allows publishing simulation models on the Web and running them in any modern web browser (Wagner, 2017). The Rebel Group Protection Rackets simulation is available online at https://gnardin.github.io/RebelGroups and the source-code is available at https://github.com/gnardin/RebelGroups/releases v1.0.

\section{Experiments}

This section describes and examines two kinds of civil war experiments, one hypothetical related to security factors (Sect.4.1) and another resembling the conditions of Somalia since 1992 (Sect. 4.2).

\footnotetext{
${ }^{4}$ More information about OESjs is available at https://sim4edu.com.
} 


\subsection{Security Experiments}

We conduct experiments aimed at explaining the dynamics of rebel fighting, their impacts on the economy, and the importance of rebel groups' economic bases of support to their sustainability in the context of a civil war. In particular, we analyze how security factors influence the dynamics of a civil war by varying the initial strength (Sect. 4.1.1) and initial allocation of Enterprises (Sect. 4.1.2).

The hypothetical scenarios in these experiments use combinations of parameter values that represent real-world inter-rebel group configurations. These scenarios are based on 3-actor settings in which three different rebel groups strive for hegemony. Each experiment scenario varies just one parameter value in relation to the baseline, whose values are shown in Table 2. These values were chosen for demonstration purposes with the exception of rebel costs, for which there exists research on the upper and lower boundaries of rebel group expenses as explained in the following paragraphs.

To estimate rebel costs, we neglect the start-up costs of rebel groups and focus only on maintenance costs. Wennmann (2009) calculates different cost ranges depending on the intensity of the conflict. We use present-day Somalia as an example of medium-intensity conflict and apply Wennmann's estimations accordingly. The estimated cost to recruit 1000 rebels ranges between US $\$ 2.5$ million and US\$16.2 million. Al-Shabaab, the current primary militant organization in Somalia, numbered between 7000 and 9000 rebels in 2014 (BBC News, 2017). Because weapon supplies and maintenance costs are relatively inexpensive in this case, we can estimate maintenance costs as US\$3.5 million per year. Thus, one rebel should cost US\$291 per 30-day period. ${ }^{5}$

Table 2 Baseline input parameter values to the experimental scenarios

\begin{tabular}{l|l}
\hline Parameter & Value \\
\hline Simulation End Time & 365 \\
\hline Number Enterprises & 3000 \\
\hline Income & $(200,50)^{\mathrm{b}}$ \\
\hline Income Frequency & 1 \\
\hline Flee Probability & $50 \%$ \\
\hline Flee Threshold & 3 \\
\hline
\end{tabular}

\begin{tabular}{|c|c|}
\hline Parameter & Value \\
\hline Number Rebel Groups & 3 \\
\hline$R G$ Size $e^{\mathrm{a}}$ & 300 \\
\hline$R G$ Prop. Enterprises ${ }^{\mathrm{a}}$ & $33 \%$ \\
\hline$R G$ Extortion Rate ${ }^{\mathrm{a}}$ & $10 \%$ \\
\hline$R G$ Rebel Cost $t^{\mathrm{a}}$ & US\$291 \\
\hline RG Recruit Threshold ${ }^{\mathrm{a}}$ & $80 \%$ \\
\hline RG Recruit Rate R $^{\mathrm{a}}$ & $50 \%$ \\
\hline$R G$ Demand Frequency ${ }^{\mathrm{a}}$ & $(30,2)^{\mathrm{b}}$ \\
\hline$R G$ Expand Frequency ${ }^{\mathrm{a}}$ & $(30,2)^{\mathrm{b}}$ \\
\hline Fight Expansion & 50 \\
\hline
\end{tabular}

${ }^{\text {a }}$ List with number of elements equal to the Number Rebel Groups with all element values the same

${ }^{\mathrm{b}}$ Mean and standard deviation defining a normal distribution

\footnotetext{
${ }^{5}$ In the future, these values may be modified to match other empirical cases.
} 
All experiment scenarios are replicated 100 times, ${ }^{6}$ each replication using one different random seed. All experiment scenarios use the same ordered set of random seeds. Specifying the random seed permits obtaining the same results as presented in this study, as otherwise probabilistic processes result in deviations.

The analyses of the experiment scenarios are based on a set of output variables: Number of Extortions, Number of Lootings, Number of Expansions, Number of Alliances, Number of Expansion Reports, Number of Fled Enterprises, Number of Recruitments, Number of Rebel Expels, and Number of Rebel Deaths. The results are calculated as the mean and standard deviation of the results of the 100 replications performed for each experiment scenario. Subsequently, we use the Wilcox Rank-Sum test (see Wilcoxon, 1945) to identify whether the change in scenario configurations entails statistically significant effects on the output variables. We chose the Wilcox Rank-Sum test because we cannot assume that the output values are normally distributed.

\subsubsection{Rebel Group Strength}

The first experiment evaluates the influence of different initial power distributions among Rebel Groups, ranging from an equally balanced to a more hierarchical setting. The experiment is composed of three scenarios that differ in the initial number of rebels of each Rebel Group (see RG Strength in Table 3). In scenario

Table 3 Results (mean and standard deviation) of the Rebel Group Strength experiment that varies the initial power distributions among Rebel Groups, ranging from an equally balanced (RGS1), to one powerful Rebel Group (RGS2) to a more hierarchical setting (RGS3)

\begin{tabular}{l|l|l|l}
\hline \multirow{2}{*}{ RG Strength $^{\mathrm{a}}$} & \multicolumn{3}{|l}{ Rebel group strength (RGS) experiment scenarios } \\
\cline { 2 - 4 } & RGS1 & RGS2 & RGS3 \\
\hline Number of Extortions & {$[300,300,300]$} & {$[300,150,150]$} & {$[300,150,75]$} \\
\hline Number of Looting & $3651 \pm 1108.21$ & $3821 \pm 1406.26$ & $4043 \pm 1337.99$ \\
\hline Number of Expansions & $5122 \pm 203.76$ & $5108 \pm 230.18$ & $5086 \pm 233.04$ \\
\hline Number of Alliances & $19 \pm 4.02$ & $19 \pm 3.89$ & $19 \pm 4.53$ \\
\hline Number of Fights & $0.05 \pm 0.22$ & $0.08 \pm 0.27$ & $0.1 \pm 0.3$ \\
\hline Number of Expansion Reports & $9.8 \pm 2.32$ & $9.55 \pm 2.17$ & $9.62 \pm 2.58$ \\
\hline Number of Fled Enterprises & $2851 \pm 127.63$ & $2842 \pm 149.19$ & $2823 \pm 148.75$ \\
\hline Number of Recruitments & $2197 \pm 908.77$ & $1574 \pm 687.67$ & $1413 \pm 567.98$ \\
\hline Number of Rebel Expels & $634 \pm 531.22$ & $407 \pm 408.46$ & $356 \pm 384.31$ \\
\hline Number of Rebel Deaths & $2199 \pm 619$ & $1531 \pm 477.43$ & $1329 \pm 419.18$ \\
\hline
\end{tabular}

${ }^{a}$ Values define the $R G$ Size for Rebel Groups 1, 2, and 3, respectively

\footnotetext{
${ }^{6} \mathrm{We}$ also conducted the experiments with 1000 simulations but the results remained almost identical.
} 
RGS1, Rebel Groups have equal strength, measured by the number of rebels associated with them. In scenario RGS2, one Rebel Group has twice the strength of each of the other Rebel Groups. Finally, scenario RGS3 invokes a stricter hierarchy between the Rebel Groups in which the strongest Rebel Group is twice as strong as the second strongest, and the second strongest is twice as strong as the weakest. The selection of these configurations is theoretically motivated, providing insight on the impacts of changes in the variation of individual parameters.

The results suggest that Rebel Group size exerts varying impacts on security and economic outcomes. The number of alliances and fights remain almost identical in all three scenarios and do not significantly differ across the different scenarios. However, recruitment rates are highest for the equal distribution scenario (RGS1), which indicates that power competition is most intense when no Rebel Group dominates from the outset. The Wilcox Rank test is statistically significant for both comparisons RGS1 and RGS2 $(p<0.01)$ and RGS1 and RGS3 $(p<0.01)$. The number of expelled rebels follows the same trend and is also statistically significant for both comparisons $(p<0.01)$. Expelling occurs when the costs of maintaining a large dominant force are too high to bear and capturing enterprises from opponent rebel groups does not pay for its maintenance. Due to fewer recruitments in the hierarchical scenarios (RGS2 and RGS3), the expel numbers fall. Further, the average death rates in the various scenarios differ by a wide margin of almost 1000 fewer deaths in the RGS3 scenario compared with RGS1 $(p<0.01)$. The high intensity of power competition in the first scenario translates into fights with more fighters and hence more fatalities. This is reminiscent of currently ongoing civil wars in Libya or Syria in which the involved rebel group sizes are sufficiently high to perpetuate and intensify the respective civil wars. Lastly, expansion rates do not differ and remain constant at 19 expansion events on average for each scenario, indicating that similar relative strength differences are reached in all different configurations after a short period of time. By contrast, extortion increases and looting decreases in more unequal scenarios but the results are statistically inconclusive.

\subsubsection{Enterprise Allocation}

This experiment evaluates the effects of different initial allocations of Enterprises among Rebel Groups, from a balanced to a more unbalanced distribution (see Allocation Proportions in Table 4). This experiment is composed of three scenarios in which we vary the initial number of Enterprises under the Rebel Groups' control. In scenario EA1, each Rebel Group starts with approximately the same number of Enterprises. In scenario EA2, Rebel Group 1 has twice as many Enterprises than the other two Rebel Groups. Finally, in scenario EA3, Rebel Group 1 initially has control over almost two-thirds of all Enterprises, while the Rebel Group 2 and Rebel Group 3 have initially thirty and $10 \%$ of Enterprises under their control, respectively. 
Table 4 Results (mean and standard deviation) of the Enterprise Allocation experiment that varies the initial allocations of Enterprises among Rebel Groups, from a balanced (EA1) to a powerful Rebel Group (EA2) to a more unbalanced and hierarchical distribution (EA3)

\begin{tabular}{l|l|l|l}
\hline \multirow{2}{*}{} & \multicolumn{3}{|l}{ Enterprise allocation (EA) experiment scenarios } \\
\cline { 2 - 4 } & EA1 & EA2 & EA3 \\
\hline Allocation Proportions $^{\mathrm{a}}$ & {$[34 \%, 33 \%, 33 \%]$} & {$[50 \%, 25 \%, 25 \%]$} & {$[60 \%, 30 \%, 10 \%]$} \\
\hline Number of Extortions & $3651 \pm 1108.21$ & $3466 \pm 1052.23$ & $3836 \pm 1239.10$ \\
\hline Number of Looting & $5122 \pm 203.76$ & $5163 \pm 169.03$ & $5124 \pm 180.96$ \\
\hline Number of Expansions & $19 \pm 4.02$ & $20 \pm 3.97$ & $19 \pm 3.36$ \\
\hline Number of Alliances & $0.05 \pm 0.22$ & $0.05 \pm 0.22$ & $0.04 \pm 0.20$ \\
\hline Number of Fights & $9.8 \pm 2.32$ & $9.82 \pm 2.39$ & $9.54 \pm 2.24$ \\
\hline Number of Expansion Reports & $6.45 \pm 2.95$ & $6.72 \pm 2.85$ & $6.21 \pm 2.17$ \\
\hline Number of Fled Enterprises & $2851 \pm 127.63$ & $2874 \pm 108.96$ & $2852 \pm 123.22$ \\
\hline Number of Recruitments & $2197 \pm 908.77$ & $2037 \pm 783.10$ & $1714 \pm 810.87$ \\
\hline Number of Rebel Expels & $635 \pm 531.22$ & $623 \pm 545.54$ & $575 \pm 471.30$ \\
\hline Number of Rebel Deaths & $2199 \pm 619$ & $2084 \pm 519.54$ & $1793 \pm 502.07$ \\
\hline
\end{tabular}

${ }^{a}$ Values define the RG Prop. Enterprises for Rebel Groups 1, 2, and 3, respectively

The results show that the variation in the output for extortions, recruitments, and deaths is statistically significant in the comparison between EA2 and EA3 $(p<0.05)$ (see Table 4). Since EA1 is not statistically different to each scenario (EA2 and EA3), the argument that there can be a trend discerned in the distribution of enterprises cannot be corroborated. Instead, EA3 appears to constitute an idiosyncratic scenario which reports the lowest deaths and recruitment rates due to its highly unequal access to revenues for rebels. The skewed allocation of enterprises between the different rebel groups put the weakest rebel group at such a disadvantage that fights are less intensive with lower casualty rates. In turn, this does not translate in fiercer competition between the more affluent rebel groups as evident by the low number of recruitments. Having a weak rebel group from the outset changes the dynamics of a civil war by reducing the expected average death toll compared to conditions in which revenue collection is sufficient for each rebel group to engage in active violent competition. From corporate perspective, this scenario (EA3) is most desirable compared to the other two scenarios as higher extortion rates are tantamount to longer survival during the civil war (which is not equal to survive the entire civil war as fleeing rates are very similar).

\subsection{Somalia Case Study}

We now consider the dynamics of a case that resembles the Rebel Group configuration of a historical example: the civil war conditions of Somalia since 1992. Somalia is an applicable case due to its relative level of anarchy since the collapse of a longstanding dictatorship (Leeson, 2007; Powell et al., 2008). 


\subsubsection{Historical Background}

Somalia was led by dictator Mohammed Siad Barre until the Somali Civil War in 1991, in which popular dissatisfaction with Barre's regime resulted in his overthrow. As a result of longstanding interclan tensions that Barre had fueled in his attempt to maintain his grip on power, the country exploded into multiple factions competing among one another for power and spoils. This led to a humanitarian disaster, prompting interventions by the United Nations and the USA (Baumann et al., 2004). However, by that time many militarized groups had proliferated and established bases of support in different areas of the country. The northern region of the country consolidated under the umbrella government of Somaliland, and the southern capital of Mogadishu collapsed into disarray (Leeson, 2007; Powell et al., 2008).

Many organizations emerged in the southern competition for power, some of the most prominent including the United Somali Congress/Somali Salvation Alliance (USC/SSA), the United Somali Congress/Somali National Alliance (USC/SNA), the Southern Somali National Movement (SSNM), the United Somali Party (USP), the Somali National Front (SNF), the Somali Asal Muki Organization (SAMO), the Somali Patriotic Movement (SPM), and the Somali National Union (SNU) (Baumann et al., 2004). Other small, religious-based militias also emerged, alongside local clan militias. Following the attack on U.S. Army personnel during a raid against militia leader General Mohamed Farah Aideed of the USC/SNA that killed nineteen US soldiers, the USA withdrew its troops and numerous attempts by the international community to broker peace subsequently failed (Baumann et al., 2004).

While the northern provisional government of Somaliland presided over a shaky peace, the rest of Somalia remained mired in overall instability and virtual anarchy (Leeson, 2007; Powell et al., 2008). In 2006 the Islamic Courts Union (ICU) managed to consolidate control over most of southern Somalia and implement Sharia law, unifying much of the country and establishing a degree of security. However, opposition organizations aligned with the transitional government challenged the ICU and fought with the support of the USA and Ethiopia, ultimately leading to ICU's withdrawal and defeat. Radical elements of the organization splintered off, forming new militant organizations such as the al-Qaeda-linked al-Shabaab. A new coalition Federal Government of Somalia (FGS) was formed with the support of foreign states, but this government has continually struggled against attacks by al-Shabaab, which holds substantial territory and at one point even controlled the capital city of Mogadishu (Ahmad, 2015).

With the help of international military support, al-Shabaab's territory has been significantly reduced since 2012, yet it regularly carries out bombings and makes grabs for territory. Violence also continues to occur between rival clans and subclans, and other armed militia groups. Due to the ongoing conflict, much if not most 
of the country lives under relative anarchy of federal or local government control. These conditions make Somalia a prime case for modeling economic opportunism in an atmosphere of insecurity. Al-Shabaab engages in extortionist activity against local businesses in order to finance its war-making activities, and it uses its violent attacks to threaten, intimidate, and punish civilians in order to continue this extortion (Ahmad, 2015). As a result, civilians often flee to neighboring countries, creating a continual refugee crisis. Al-Shabaab also engages in sophisticated information campaigns to recruit new fighters, facilitating its expansion and continual battles against the Western and Ethiopia-backed government.

\subsubsection{Data and Experimentation}

We perform an experiment simulating three scenarios that each represents one of the three different stages in Somalia's conflict: first, a system with nine Rebel Groups of the same size and characteristics, in equal competition for power; second, a system with nine Rebel Groups but with varying sizes and extortion populations; and third, a system with one primary strong Rebel Group among many much smaller groups. The values used in the model are based on published estimations of group size and extortion of local populations, as well as other rebel and demographic characteristics (Abbink, 2009; Clarke, 1992; UNFPA, 2016). Each experiment scenario varies the RG Size and RG Prop. Enterprises values, while all other values are fixed as shown in Table 5.

All experiment scenarios are replicated 100 times, each replication using one different random seed. The analyses of the experiment scenarios are based on a set of output variables whose values are calculated as the mean and standard deviation of the results of the 100 replications performed for each experiment scenario.

The first scenario (SO1) represents the period immediately following the collapse of the Barre regime, in which multiple groups increased in size and capability in the fight against Barre but had not yet dominated one another. The values for all 9 Rebel

Table 5 Somalia baseline input parameter values to the experimental scenarios

\begin{tabular}{l|l}
\hline Parameter & Value \\
\hline Simulation End Time & 365 \\
\hline Number Enterprises & 3000 \\
\hline Income & $(200,50)^{\mathrm{b}}$ \\
\hline Income Frequency & 1 \\
\hline Flee Probability & $50 \%$ \\
\hline Flee Threshold & 3 \\
\hline
\end{tabular}

\begin{tabular}{|c|c|}
\hline Parameter & Value \\
\hline Number Rebel Groups & 9 \\
\hline$R G$ Extortion Rate a $^{\mathrm{a}}$ & $10 \%$ \\
\hline$R G$ Rebel Cost $t^{\mathrm{a}}$ & US\$291 \\
\hline RG Recruit Threshold ${ }^{\mathrm{a}}$ & $80 \%$ \\
\hline RG Recruit Rate & $50 \%$ \\
\hline$R G$ Demand Frequency ${ }^{\mathrm{a}}$ & $(30,2)^{\mathrm{b}}$ \\
\hline RG Expand Frequency ${ }^{\mathrm{a}}$ & $(30,2)^{\mathrm{b}}$ \\
\hline Fight Expansion & 1 \\
\hline
\end{tabular}

${ }^{a}$ List with number of elements equal to the Number Rebel Groups with all element values the same

${ }^{\mathrm{b}}$ Mean and standard deviation defining a normal distribution 
Group sizes are 500, and $11 \%$ for all proportion of Enterprises. The second scenario (SO2) represents the conditions approximately 1 year later once different groups began to compete with one another. The USC/SSA and the USC/SNA emerged as the two primary rival organizations, while the others maintained smaller niches in the fight as well. Here, the first two Rebel Groups have a size of 500 members, while the remaining are comprised of only 200 members. The proportion of Enterprises per Rebel Group are as follows: $18 \%, 18 \%, 1 \%, 14 \%, 4 \%, 6 \%, 14 \%, 13 \%$, and $3 \%$. These values are determined by the population distributions of the clans that each group claims to represent (Baumann et al., 2004). This assumes that the Rebel Groups each extort only from within their own clans.

The third scenario (SO3 and $\mathrm{SO}^{*}$ ) represents a post-ICU Somalia in which alShabaab is the primary extortionist Rebel Group, while many other small clan-based militias also compete locally for power. In this case, one Rebel Group is a size of 7000 , and the others are all a size of 200 , in order to represent the approximate empirical proportionality of different group sizes. The proportion of Enterprises for the first group is $50 \%$, and the remaining are each $6.25 \%$.

The results shown in Table 6 indicate most clearly that observers should expect more extortion to have taken place as power in Somalia became consolidated by a fewer number of groups. This is consistent with our theory that without peer competition, rebel groups are most likely to establish a stable and widespread racket system. In addition to increased extortion, consolidation should also lead to a decrease in other violent activity such as looting and fighting. Although we observe slight decreases in looting and fights across our experiments, these trends are not

Table 6 Experiment results of the Somalia case study

\begin{tabular}{l|l|l|l|l}
\hline \multirow{2}{*}{} & \multicolumn{4}{l}{ Somalia (SO) experiment scenarios } \\
\cline { 2 - 5 } & SO1 & SO2 & SO3 & SO3* \\
\hline Group sizes and proportions & All equal & Two stronger & One Hegemon & One Hegemon \\
\hline Number of Extortions & $641 \pm 32.98$ & $862 \pm 75.44$ & $1776 \pm 128.64$ & $2958 \pm 913.72$ \\
\hline Number of Looting & $5257 \pm 46.05$ & $5256 \pm 45$ & $5259 \pm 45.36$ & $5178 \pm 130.12$ \\
\hline Number of Expansions & $49 \pm 4.45$ & $47 \pm 4.07$ & $49 \pm 4.18$ & $47 \pm 6.96$ \\
\hline Number of Alliances & $0.68 \pm 0.75$ & $0.58 \pm 0.70$ & $0.67 \pm 0.78$ & $0.43 \pm 0.78$ \\
\hline Number of Fights & $24 \pm 4.30$ & $25 \pm 4$ & $23 \pm 4.04$ & $24 \pm 3.99$ \\
\hline Number of Expansion Reports & $14 \pm 4.01$ & $13 \pm 3.53$ & $15 \pm 3$ & $13 \pm 3.84$ \\
\hline Number of Fled Enterprises & $2999 \pm 1.03$ & $2996 \pm 5.95$ & $2999 \pm 5.03$ & $2938 \pm 92.49$ \\
\hline Number of Recruitments & $2395 \pm 307.05$ & $2481 \pm 438.79$ & $1497 \pm 186.73$ & $6172 \pm 1021.36$ \\
\hline Number of Rebel Expels & $3233 \pm 560.02$ & $1778 \pm 370.18$ & $8253 \pm 343.35$ & $8431 \pm 722.15$ \\
\hline Number of Rebel Deaths & $3660 \pm 458.63$ & $3096 \pm 379.91$ & $1841 \pm 291.42$ & $6008 \pm 773.53$ \\
\hline SOl remresents
\end{tabular}

SO1 represents the period immediately following the collapse of the Barre's regime. SO2 represents the conditions approximately 1 year later once different groups began to compete with one another. SO3 represents a post-ICU Somalia in which al-Shabaab is the primary extortionist Rebel Group, while many other small clan-based militias also compete locally for power. SO3* is similar than SO3, except that it represents the presence of substantial outside funding comprising about $80 \%$ of Rebel Group's revenue 
significant due to large standard deviation values. We would otherwise expect that, due to the high number of relatively weak groups in scenario SO1, every group should have an incentive to increase its power quickly and primarily loot rather than extort. We observe a very low level of alliances in any of the scenarios, possibly due to high plurality of competition. Overall, these results support our expectations that a greater level of extortion is reached once one group has achieved hegemony, but adjustments to the model may be necessary to lower standard deviations such that other expected patterns become more significant.

A notable pattern emerges during scenario $\mathrm{SO} 3$ in which the largest group quickly shrinks in size, with its number of fighters becoming more similar to that of its competitors. Extortion profits are insufficient to continue allocating pay to the proportionally high number of fighters used to represent al-Shabaab in this experiment. Therefore, after only a short period of time, the large group is unable to sustain itself. It does not remain a hegemon, possibly causing an unexpectedly high number of observed incidents of looting, fighting, and fled Enterprises in SO3. This may also be the cause of high numbers of rebel expels and rebel deaths. In reality, a dominant group like al-Shabaab receives a substantial portion of its income from external sources, such as foreign remittances and overseas benefactors (Keatinge, 2014). It also engages in its own trade and business practices in order to raise revenue. These sources of income, which likely enable al-Shabaab to sustain its large number of fighters and widespread activities, are not accounted for in our model.

Therefore, we perform a second simulation of the third scenario (SO3*) in which all parameters remain the same as in $\mathrm{SO}$, except in order to represent the presence of substantial outside funding comprising about $80 \%$ of revenue, we lower the cost per rebel fighter for the hegemon from US\$291 to US $\$ 50 .{ }^{7}$ Our results in SO3* show even greater extortion activity in a system with other revenue sources; the number of extortions is significantly higher than those in the first three scenarios. The number of lootings and fleeing Enterprises is slightly lower, but these results fall within the margin of error and are not statistically significant. Further, the number of fights and the number of Rebel deaths do not decrease as expected in a system with greater stability and control under one hegemon. The model captures greater financial stability, but not greater securitization. These results are consistent with theories that external funding to rebel groups actually increases violence levels and conflict severity (Fearon, 2004; Weinstein, 2006). This impact would therefore counteract economic benefits and explain the lack of decrease in looting, fighting, and deaths.

Data from the Uppsala Conflict Data Program (UCDP) show the highest numbers of civilian and combatant deaths in Somalia at the height of its collapse into civil war in 1991 and 1992 (Croicu and Sundberg, 2017; Sundberg and Melander, 2013). Conflict during this time period, in which a multitude of rebel groups competed among themselves for power, resulted in a critically higher number of refugees

\footnotetext{
$780 \%$ is a rough approximation used to represent outside funding as a substantially larger source of income than extorted funds.
} 
fleeing looting and violence at the beginning of the war than later on (Leeson, 2007; Powell et al., 2008). After 2008, once the Islamic Courts Union (ICU) achieved a monopoly of control over most areas of the country, violence ceased. However, fighting shortly resumed at a lower but consistent level as foreign-backed groups rose to oppose its power and al-Shabaab emerged, using violence to try to reestablish order and intimidate its enemies. Since its inception the group managed to maintain a steady extortion racket in areas under its control (Keatinge, 2014), which is consistent with the results of our model. Although the results do not capture the significant decrease in violence and fleeing from early levels, they do represent how extortion increases with consolidation of power over time.

Our results are also limited in that they provide no insight into the stability or security of the internal practices of a hegemonic group. For example, despite a monopoly on extortion and violence by al-Shabaab in many communities of Somalia, the violent practices exercised by the internationally condemned terrorist organization such as intimidation for extracting extortion, strict policing and law enforcement that utilizes corporal punishment, and acts of terrorism result in an overall instability for civilian residents. Further, their monopoly on power is inconsistent, and clashes rise and fall in frequency as al-Shabaab loses and regains control of territory. Hegemonic control therefore does not necessarily equate to overall improvement in stability and security. However, our model does demonstrate some of the immediate effects of political contestation between different numbers of groups in civil war.

\section{Conclusion and Discussion}

The experiments using our agent-based simulation model indicate that unequal power distribution between rebel groups leads to less fighting, less rebel recruitment, and lower death rates in a civil war. Unequal enterprise allocation similarly affects extortion, with the highest incidence rate when one hegemon overwhelmingly dominates. Ultimately, wars with unequal power distributions may be more likely to end faster, with fewer fatalities. This finding supports existing research on the effects of rebel group strength parity, which may impede conflict termination due to miscalculations and bargaining failures (Humphreys, 2005, p. 504). It contradicts, however, findings that parity could lead to earlier termination due to the prolonged costs of a stalemate (Zartman, 2000). We also find that a more hegemonic system results in greater economic stability. This does not necessarily result in greater security, as demonstrated by the Somalia case study. Other factors such as external funding of rebel groups and the brutality of their internal practices may cause violent activity despite consolidation of extortion practices.

Our agent-based model provides an important methodological supplement to existing studies of conflict that use quantitative statistical analyses and qualitative case studies. As civil wars are highly complex dynamic systems, the evaluation of individual parameters and their impacts on civil wars must be understood 
and investigated against the backdrop of continually changing environments. The simulation experiments provide us with expectations for the trajectories of conflicts, depending on various economic and security conditions. The inclusion of probabilistic functions allows us to account for random variation or error that could capture the unpredictability of real-world events. We encourage interested readers to explore various initial settings to develop an understanding of civil war dynamics based on the assumptions laid out in this study (executable at https:/gnardin.github. io/RebelGroups).

Future adjustments to the model could include incorporating external influences such as foreign military intervention or outside sources of rebel funding. The difference in results between scenarios $\mathrm{SO} 3$ and $\mathrm{SO}^{*}$ in the Somalia experiment demonstrates the potential significance of this addition. Another potential improvement could be the inclusion of spatial data. The model currently does not account for "space" or "territory," which are instead represented through the allocation of Enterprises. Spatial data could be used to place restrictions on Rebel Groups' directions of expansion and initiate balancing. Lastly, since the programming code remains open-source, interested readers can engage in modifications and alter our assumptions. For instance, event types like fighting or expansions can be modified to reflect different understandings of these behaviors. New event types can be created that are not included in the model (e.g., intervention or the provision of foreign aid). Parameters can also be thought to represent rebel group characteristics. For instance, religious and ideologically based rebel groups like Al-Shabaab might have higher expansion rates compared to ethnic based rebel groups in Somaliland.

Apart from its scientific contributions to the field of conflict studies, agent-based models of civil wars have the strong potential to contribute to informed policymaking by allowing users to predict the range of possible ways in which a civil war can evolve. Their usefulness is dependent on successful gathering of data to reflect realistic conditions as closely as possible. It could potentially serve as a useful tool for political decision-making, as model results may provide clues for the expected intensity of wars and their possible impacts on local economies in conflict countries. For instance, an adjusted model that takes foreign influences into account could attempt to simulate the potential outcomes of a currently looming civil war in Venezuela. Using information on the strength of potential rebel groups based on the opposition as well as specifying additional autonomous actors like the army and local groups (colectivos) would allow one to simulate the impact of decisions like the provision of military aid to either group on ongoing civil war dynamics.

\section{References}

Abbink, J. (2009). The total Somali clan genealogy. ASC Working Paper 84. Leiden: African Study Centre.

Ahmad, A. (2015). The security Bazaar: Business interests and Islamist power in civil war Somalia. International Security, 39(3), 89-117. 
Barter, S. J. (2012). Unarmed forces: Civilian strategy in violent conflicts. Peace and Change, 37(4), 544-571.

Baumann, R. F., Yates, L. A., \& Washington, V. F. (2004). My clan against the world: US and coalition forces in Somalia, 1992-1994. Fort Leavenworth: Combat Studies Institute Press.

BBC News (2017). Who are Somalia's al-Shabab? Retrieved from https://www.bbc.com/news/ world-africa-15336689. Accessed 13 Dec 2018.

Cederman, L.-E., \& Vogt, M. (2017). Dynamics and logics of civil war. Journal of Conflict Resolution, 61(9), 1992-2016.

Clarke, W. S. (1992). Somalia: Background information for operation Restore Hope 1992-93. Carlisle Barracks: Strategic Studies Institute. SSI Special Report AD-A259 777.

Collier, P., \& Duponchel, M. (2013). The economic legacy of civil war: Firm-level evidence from Sierra Leone. Journal of Conflict Resolution, 57(1), 65-88.

Collier, P., Hoeffler, A., \& Rohner, D. (2008). Beyond greed and grievance: Feasibility and civil war. Oxford Economic Papers, 61(1), 1-27.

Croicu, M., \& Sundberg, R. (2017). UCDP GED codebook version 18.1. Uppsala: Department of Peace and Conflict Research, Uppsala University. Technical report.

Cunningham, K. G. (2013). Actor fragmentation and civil war bargaining: How internal divisions generate civil conflict. American Journal of Political Science, 57(3), 659-672.

Daxecker, U., \& Prins, B. C. (2017). Financing rebellion. Journal of Peace Research, 54(2), 215230.

Epstein, J. M. (2002). Modeling civil violence: An agent-based computational approach. Proceedings of the National Academy of Sciences, 99(Supplement 3), 7243-7250.

Escribà-Folch, A., Meseguer, C., \& Wright, J. (2018). Remittances and protest in dictatorships. American Journal of Political Science, 62(4), 889-904.

Fearon, J. (2004). Why do some civil wars last so much longer than others? Journal of Peace Research, 41(3), 275-301.

Fjelde, H., \& Nilsson, D. (2012). Rebels against rebels. Journal of Conflict Resolution, 56(4), 604-628.

Fonoberova, M., Mezić, I., Mezić, J., \& Mohr, R. (2018). An agent-based model of urban insurgence: Effect of gathering sites and Koopman mode analysis. PLoS One, 13(10), 1-25.

Goh, C. K., Quek, H. Y., Tan, K. C., \& Abbass, H. A. (2006). Modeling civil violence: An evolutionary multi-agent, game theoretic approach. In 2006 IEEE International Conference on Evolutionary Computation (pp. 1624-1631). Piscataway, NJ: IEEE.

Humphreys, M. (2005). Natural resources, conflict, and conflict resolution: Uncovering the mechanisms. Journal of Conflict Resolution, 49(4), 508-537.

Ikelegbe, A. (2006). The economy of conflict in the oil rich Niger delta region of Nigeria. African and Asian Studies, 5(1), 23-55.

Johnson, C. (2015). Keeping the peace after partition: Ethnic minorities, civil wars, and the third generation ethnic security dilemma. Civil Wars, 17(1), 25-50.

Kalyvas, S. N. (2006). The logic of violence in civil war. Cambridge: Cambridge University Press.

Keatinge, T. (2014). The role of finance in defeating Al-Shabaab. London: Royal United Services Institute. Technical report.

Leeson, P. T. (2007). Better off stateless: Somalia before and after government collapse. Journal of Comparative Economics, 35(4), 689-710.

Lemos, C., Lopes, R. J., \& Coelho, H. (2016). On legitimacy feedback mechanisms in agent-based modeling of civil violence. International Journal of Intelligent Systems, 31(2), 106-127.

Lujala, P. (2008). Deadly combat over natural resources. Journal of Conflict Resolution, 53(1), $50-71$.

Lujala, P., Gleditsch, N. P., \& Gilmore, E. (2005). A diamond curse? Journal of Conflict Resolution, 49(4), 538-562.

Nardin, L. G., Andrighetto, G., Conte, R., Székely, Á., Anzola, D., Elsenbroich, C., et al. (2016). Simulating protection rackets: A case study of the Sicilian mafia. Autonomous Agents and Multi-Agent Systems, 30(6), 1117-1147. 
Nygård, H. M., \& Weintraub, M. (2014). Bargaining between rebel groups and the outside option of violence. Terrorism and Political Violence, 27(3), 557-580.

Olson, M. (1993). Dictatorship, democracy, and development. American Political Science Review, 87(3), 567-576.

Østby, G. (2008). Polarization, horizontal inequalities and violent civil conflict. Journal of Peace Research, 45(2), 143-162.

Posen, B. R. (1993). The security dilemma and ethnic conflict. Survival, 35(1), 27-47.

Powell, B., Ford, R., \& Nowrasteh, A. (2008). Somalia after state collapse: Chaos or improvement? Journal of Economic Behavior and Organization, 67(3-4), 657-670.

Regan, P. M., \& Frank, R. W. (2014). Migrant remittances and the onset of civil war. Conflict Management and Peace Science, 31(5), 502-520.

Reno, W. (1999). Warlord politics and African states. Boulder, CO: Lynne Rienner Publishers.

Roe, P. (1999). The intrastate security dilemma: Ethnic conflict as a 'tragedy'? Journal of Peace Research, 36(2), 183-202.

Schmidt, E. (2013). Foreign intervention in Africa. Cambridge: Cambridge University Press.

Shearer, D. (2000). Aiding or abetting? Humanitarian aid and its economic role in civil war. In M. R. Berdal, \& D. M. Malone (Eds.), Greed and Grievance. Economic Agendas in Civil Wars (pp. 189-203). Boulder, CO: Lynne Rienner Publishers.

Spaniel, W., \& Bills, P. (2016). Slow to learn. Journal of Conflict Resolution, 62(4), 774-796.

Steele, A. (2009). Seeking safety: Avoiding displacement and choosing destinations in civil wars. Journal of Peace Research, 46(3), 419-429.

Sundberg, R., \& Melander, E. (2013). Introducing the UCDP georeferenced event dataset. Journal of Peace Research, 50(4), 523-532.

Tilly, C. (1985). War making and state making as organized crime. In P. Evans, D. Rueschemeyer, \& T. Skocpol (Eds.), Bringing the state back in (pp. 169-191). Cambridge: Cambridge University Press.

UNFPA (2016). Population composition and demographic characteristics of the Somali people (Vol. 2). http://analyticalreports.org/pdf/UNFPA_PESS_Vol_2.pdf.

Wagner, G. (2017). Sim4edu.com — web-based simulation for education. In 2017 Winter simulation conference (WSC). Piscataway, NJ: IEEE.

Wagner, G. (2018). Information and process modeling for simulation — Part I: Objects and events. Journal of Simulation Engineering, 1, 1-25.

Walt, S. M. (1985). Alliance formation and the balance of world power. International Security, 9(4), 3.

Walter, B. F. (2017). The new new civil wars. Annual Review of Political Science, 20(1), 469-486.

Waltz, K. N. (1979). Theory of international politics (1st edn.). Boston, MA: McGraw-Hill.

Weinstein, J. M. (2005). Resources and the information problem in rebel recruitment. Journal of Conflict Resolution, 49(4), 598-624.

Weinstein, J. M. (2006). Inside rebellion: The politics of insurgent violence. Cambridge: Cambridge University Press.

Wennmann, A. (2009). Grasping the financing and mobilization cost of armed groups: A new perspective on conflict dynamics. Contemporary Security Policy, 30(2), 265-280.

Wennmann, A. (2011). Economic dimensions of armed groups: Profiling the financing, costs, and agendas and their implications for mediated engagements. International Review of the Red Cross, 93(882), 333-352.

Wilcoxon, F. (1945). Individual comparisons by ranking methods. Biometrics Bulletin, 1(6), $80-83$. 
Wood, R. M. (2014). From loss to looting? Battlefield costs and rebel incentives for violence. International Organization, 68(04), 979-999.

Zartman, I. W. (2000). Ripeness: The hurting stalemate and beyond. In P. C. Stern, \& D. Druckman (eds), International conflict resolution after the cold war (pp. 225-250). Washington, DC: National Academy Press.

Open Access This chapter is licensed under the terms of the Creative Commons Attribution 4.0 International License (http://creativecommons.org/licenses/by/4.0/), which permits use, sharing, adaptation, distribution and reproduction in any medium or format, as long as you give appropriate credit to the original author(s) and the source, provide a link to the Creative Commons licence and indicate if changes were made.

The images or other third party material in this chapter are included in the chapter's Creative Commons licence, unless indicated otherwise in a credit line to the material. If material is not included in the chapter's Creative Commons licence and your intended use is not permitted by statutory regulation or exceeds the permitted use, you will need to obtain permission directly from the copyright holder. 